\title{
PROTECTIVE EFFECTS OF DIMETHYL AMILORIDE AGAINST POSTISCHEMIC MYOCARDIAL DYSFUNCTION IN RABBIT HEARTS: PHOSPHORUS 31-NUCLEAR MAGNETIC RESONANCE MEASUREMENTS OF INTRACELLULAR PH AND CELLULAR ENERGY
}

Akira Koike, $\mathrm{MD}^{\mathrm{a}}$

Toshiaki Akita, MD

Yoshihiro Hotta, $\mathrm{PhD}^{\mathrm{b}}$

Kazumi Takeya, $\mathrm{PhD}^{\mathrm{b}}$

Itsuo Kodama, $\mathrm{MD}^{\mathrm{c}}$

Mitsuya Murase, $\mathrm{MD}^{\mathrm{a}}$

Toshio Abe, MD

Junji Toyama, MD $^{\mathrm{c}}$
The effects of 5 -( $N, N$-dimethyl)amiloride, a potent and specific $\mathrm{Na}^{+}-\mathrm{H}^{+}$ exchange inhibitor, were investigated in isolated perfused rabbit hearts subjected to ischemia and reperfusion. Phosphorus 31-nuclear magnetic resonance spectroscopy was used to monitor intracellular $\mathrm{pH}$, creatine phosphate, $\beta$-adenosine triphosphate, and inorganic phosphate. After cardioplegic arrest with St. Thomas' Hospital solution, normothermic $\left(37^{\circ} \mathrm{C}\right)$ global ischemia was induced for 45 minutes, and the hearts were reperfused for 50 minutes. Dimethyl amiloride at $10 \mu \mathrm{mol} / \mathrm{L}$, which has minimal inotropic and chronotropic effects on the nonischemic heart, was added to the cardioplegic solution. Treatment with dimethyl amiloride reduced the elevation of left ventricular end-diastolic pressure during and after the ischemia and improved the postischemic recovery of developed pressure from $76 \% \pm 3.2 \%$ at 30 minutes of reperfusion in control hearts $(n=6)$ up to $99 \% \pm 1.9 \%$ in hearts treated with dimethyl amiloride $(n=8)$. Dimethyl amiloride did not affect the decline in intracellular $\mathrm{pH}$ during ischemia for up to 30 minutes but enhanced the intracellular acidosis thereafter. The intracellular $\mathrm{pH}$ at the end of ischemia was $6.21 \pm 0.05$ in control hearts compared with $5.24 \pm 0.17$ in hearts treated with dimethyl amiloride $(p<\mathbf{0 . 0 5})$. During reperfusion, intracellular $\mathrm{pH}$ of hearts treated with dimethyl amiloride was less than control for 5 minutes, but subsequent recovery of intracellular $\mathrm{pH}$ was similar to control. Treatment with dimethyl amiloride did not affect creatine phosphate breakdown, inorganic phosphate accumulation, and $\beta$-adenosine triphosphate depletion during $\mathbf{4 5}$ minutes of ischemia. The creatine phosphate resynthesis and inorganic phosphate reduction during reperfusion were also unaffected. These findings suggest that $\mathrm{Na}^{+}-\mathrm{H}^{+}$exchange plays an important role not only during reperfusion but also during ischemia for the development of postischemic cardiac dysfunction most likely by inducing primary $\mathrm{Na}^{+}$and secondary $\mathrm{Ca}^{2+}$ overload. Specific $\mathrm{Na}^{+} \cdot \mathrm{H}^{+}$exchange inhibitors like dimethyl amiloride would have a potential therapeutic profile in cardiac surgery, especially if added before ischemia. (J Thorac Cardiovasc Surg 1996;112:765-75)
From the Department of Thoracic Surgery, School of Medicine,

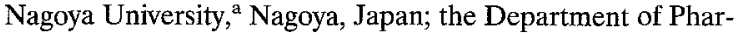
macology, Aichi Medical University, ${ }^{b}$ Aichi, Japan; and the Departments of Circulation and Humoral Regulation, ${ }^{c}$ Research Institute of Environmental Medicine, Nagoya University, Nagoya, Japan.

Received for publication July 24, 1995; revisions requested Nov. 14, 1995; revisions received April 2, 1996; accepted for publication April 3, 1996.

Address for reprints: Itsuo Kodama, MD, Department of Humoral Regulation, Research Institute of Environmental Medicine, Nagoya University, Furo-cho, Chikusa-ku, Nagoya 46401, Japan.
Dharmacologic evidence for the involvement of sarcolemmal $\mathrm{Na}^{+}-\mathrm{H}^{+}$exchange in myocardial ischemia-reperfusion injury has emerged from many experimental studies showing various salutary effects of $\mathrm{Na}^{+}-\mathrm{H}^{+}$exchange inhibitors, including amiloride and other organic compounds. ${ }^{1-3}$ In animal experiments in which rats, guinea pigs, rabbits, and dogs were used, many investigators have dem-

Copyright $(\mathcal{C} 1996$ by Mosby-Year Book, Inc.

$0022-5223 / 96 \$ 5.00+0 \quad \mathbf{1 2 / 1 / 7 3 9 1 4}$ 
onstrated that treatment of hearts with amiloride or other compounds having more specific inhibitory action against $\mathrm{Na}^{+}-\mathrm{H}^{+}$exchange improves postischemic contractile recovery, ${ }^{4-7}$ reduces reperfusion arrhythmias, ${ }^{8}$ diminishes creatine kinase efflux during reperfusion, ${ }^{6}$ preserves microscopic cellular integrity, ${ }^{9}$ or reduces $\mathrm{Na}^{+_{i}}$ and $\mathrm{Ca}^{2+_{i}}$ accumulation. ${ }^{4,10}$ Regarding the precise nature of their beneficial effects, however, several issues remain to be resolved.

Controversy exists as to whether cardiac protection by $\mathrm{Na}^{+}-\mathrm{H}^{+}$exchange inhibitors is limited to reperfusion or would also occur under ischemic conditions. ${ }^{2,3} \mathrm{Na}^{+}-\mathrm{H}^{+}$exchange inhibitors were shown to have a certain protective effect if the compound was given only during reperfusion. ${ }^{6-9}$ Nevertheless, protection is also present during ischemia $^{9,11,12}$ and is even more pronounced if the inhibitor is given during ischemia and reperfusion. ${ }^{9}$ The protective effects of $\mathrm{Na}^{+}-\mathrm{H}^{+}$exchange inhibitors were associated with the preservation of highenergy phosphates in some studies, ${ }^{9,13}$ but not in others. ${ }^{4,10}$

The cardioprotective effects of $\mathrm{Na}^{+}-\mathrm{H}^{+}$exchange inhibitors have the potential to be clinically useful. In view of the preclinical data, the most promising indications for the inhibitors include the typical ischemia-reperfusion situation, in which the start of ischemia and reperfusion is known and sufficient concentrations of the compound can be applied to the heart. This is the case in cardiac surgery. ${ }^{3}$ During cardiac operations, the contraction of the heart has to be stopped by a cardioplegic solution. The heart is disconnected from systemic blood flow and is reperfused at the end of the procedure. Various protective drugs are, therefore, usually applied to the cardioplegic solution so that their concentration in the heart will remain high enough without affecting other organs. To our knowledge, however, little information is available as to the cardioprotective effects of $\mathrm{Na}^{+}-\mathrm{H}^{+}$exchange inhibitors against ischemia-reperfusion injury when applied to the cardioplegic solution.

The current study was designed to gain further insight into the mechanism of cardioprotective action of $\mathrm{Na}^{+}-\mathrm{H}^{+}$exchange inhibitors and their potential therapeutic profile in cardiac surgery. We investigated the effects of 5-(N,N-dimethyl) amiloride (DMA), a more potent and more specific inhibitor of $\mathrm{Na}^{+}-\mathrm{H}^{+}$exchange than amiloride, ${ }^{8,14}$ on the sequential changes of left ventricular contractility, intracellular $\mathrm{pH}\left(\mathrm{pH}_{\mathrm{i}}\right)$, and high-energy phos- phates in isolated perfused rabbit hearts subjected to normothermic global ischemia during cardioplegic arrest and subsequent reperfusion. DMA was applied to the cardioplegic solution, and $\mathrm{pH}_{\mathrm{i}}$ and energy metabolism were monitored by use of phosphorus 31-nuclear magnetic resonance (NMR) spectroscopy.

\section{Materials and methods}

Preparation. Hearts were obtained from young white rabbits, 4 to 7 weeks old, weighing 500 to $800 \mathrm{gm}$. After intravenous administration of heparin (1000 IU) and thiamylal sodium $(20 \mathrm{mg} / \mathrm{kg})$, hearts were quickly excised and placed in cold $\left(4^{\circ} \mathrm{C}\right)$ perfusion solution. The aorta was cannulated for nonrecirculating Langendorff perfusion at a constant hydrostatic pressure $\left(75 \mathrm{~cm} \mathrm{H}_{2} \mathrm{O}\right)$. The control perfusate was a modified phosphate-free KrebsHenseleit bicarbonate buffer solution of the following composition (in millimoles per liter): $\mathrm{NaCl}, 118 ; \mathrm{KCl}, 5.9$; $\mathrm{NaHCO}_{3}, 25 ; \mathrm{MgSO}_{4}, 1.2 ; \mathrm{CaCl}_{2}, 2.5$; and glucose, 5.5. The solution was equilibrated with $95 \%$ oxygen and $5 \%$ carbon dioxide to achieve a $\mathrm{pH}$ of 7.4 at $37^{\circ} \mathrm{C}$. A latex balloon (size $4.3 \mathrm{~mm}$ in maximal diameter and $6.3 \mathrm{~mm}$ in length, Hirokawa, Niigata, Japan) was introduced into the left ventricle via the left atrium and connected to a strain-gauge transducer (MIP-5100, Baxter, Tokyo, Japan) for measurement of isovolumic left ventricular pressure. The balloon was filled with distilled water containing a $0.5 \mathrm{~mol} / \mathrm{L}$ concentration of methylene diphosphonic acid as external standard of the NMR spectral reference. The left ventricular end-diastolic pressure was adjusted to 5 $\mathrm{mm} \mathrm{Hg}$ during the equilibration period in each heart, and the volume was unchanged during the experiments. The left ventricular developed pressure was calculated by subtracting left ventricular end-diastolic pressure from left ventricular systolic pressure. The maximum rate of contraction and relaxation $( \pm \mathrm{dp} / \mathrm{dt})$ was obtained by electronic differentiation. The pulmonary artery was incised to ensure adequate right ventricular venting. Myocardial temperature was maintained at $37^{\circ} \pm 0.5^{\circ} \mathrm{C}$ by a waterjacketed perfusion line and a continuous stream of air around the sample tube of NMR.

All animals have received humane care in compliance with the "Principles of Laboratory Animal Care" formulated by the National Society for Medical Research and the "Guide for the Care and Use of Laboratory Animals" prepared by the Institute of Laboratory Animal Resources and published by the National Institutes of Health (NIH publication No. 86-23, revised 1985).

NMR spectroscopy. In all the ischemia-reperfusion experiments, ${ }^{31} \mathrm{P}-\mathrm{NMR}$ spectra were monitored along with simultaneous recording of ventricular pressure. The heart connected to the Langendorff perfusion line was placed in a standard $20 \mathrm{~mm}$ NMR tube with the apex approximately $2.5 \mathrm{~cm}$ from the bottom of the tube, and the tube was inserted into the NMR coil. The effluent was removed from a level above the heart by a peristaltic pump, leaving the heart submerged in a fixed volume of the perfusate.

${ }^{31} \mathrm{P}-\mathrm{NMR}$ spectra were obtained at $161.8 \mathrm{MHz}$ on a GSX 400 spectrometer (Jeol Datum Co. Ltd., Tokyo, 


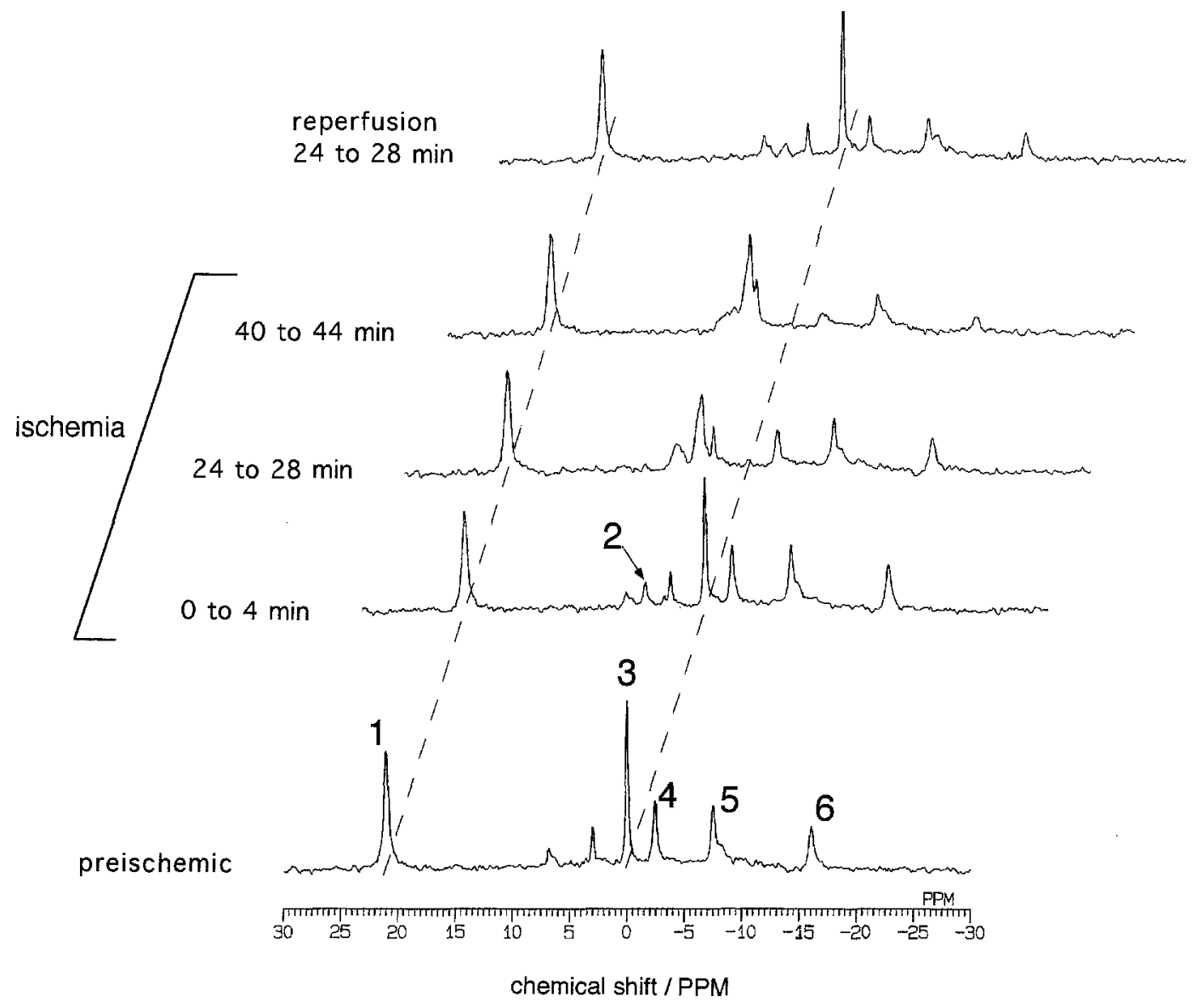

Fig. 1. ${ }^{31} \mathrm{P}-\mathrm{NMR}$ spectra obtained from an untreated (control) rabbit heart before ischemia, during ischemia, and during reperfusion. Numbered peaks are as follows: 1, methylene diphosphate; 2, intracellular $\mathrm{Pi} ; 3, \mathrm{PCr} ; 4,5$, and $6, \gamma-, \alpha$, and $\beta$-phosphate group of ATP, respectively.

Japan) equipped with a 9.4-tesla vertical-bore magnet. For each spectrum, 90 free-induction decays ( 4 minutes) were accumulated after 45 -degree flip-angle pulses (18 $\mu \mathrm{sec}$ ) by use of 4096 data points and $15.015 \mathrm{kHz}$ spectral width at a repetition time of 2 seconds. Accumulated free-induction decays were exponentially filtered, resulting in $30 \mathrm{~Hz}$ line broadening. Quantification of inorganic phosphate $(\mathrm{Pi})$, phosphocreatine $(\mathrm{PCr})$, and $\beta$-adenosine triphosphate (ATP) in the myocardium was achieved by integration of areas under individual peaks of interest in each spectrum using a specially designed gaussian line fitting software (Datum Station ALICE, Jeol Datum) installed in a computer (NEC 9801, NEC Co., Ltd., Tokyo, Japan). ${ }^{15}$ Values of PCr and ATP were expressed as a percentage relative to the individual spectrum obtained during the preischemic control period. Pi was expressed as a percentage of the sum of phosphate from PCr, ATP, and Pi during preischemic control perfusion ${ }^{16}$ by the equation: $\left(\mathrm{Pi} /[\mathrm{PCr}+3 \mathrm{ATP}+\mathrm{Pi}]_{\text {preischemic }}\right) \times$ $100 \%$.

$\mathrm{pH}_{\mathrm{i}}$ was measured by the chemical shift of the Pi peak relative to the $\mathrm{PCr}$ peak. The chemical shift values in parts per million were converted to $\mathrm{pH}$ units as previously described $^{17,18}$ (Fig. 1)

\section{Protocols}

Effects of DMA on mechanical performance of nonischemic hearts. Hearts were allowed to beat spontaneously with a rate ranging from 147 to 174 beats/min. After a stabilization period of 20 to 30 minutes, the perfusate was changed from the control to a solution including DMA at a concentration of $10 \mu \mathrm{mol} / \mathrm{L}$. Effects of DMA on heart rate, left ventricular systolic, end-diastolic, and developed pressure, $+\mathrm{dp} / \mathrm{dt}$, and $-\mathrm{dp} / \mathrm{dt}$ were monitored during 45 minutes of exposure to DMA and 30 minutes after the compound was washed out.

Influence of DMA on the hearts subjected to ischemia and reperfusion. After a stabilization period in the test tube of the NMR spectrometer for 20 to 30 minutes, preischemic values for left ventricular systolic, end-diastolic, and developed pressures, $\pm \mathrm{dp} / \mathrm{dt}$, and heart rate were recorded. The hearts were then perfused with St. Thomas' Hospital cardioplegic solution at $37^{\circ} \mathrm{C}$ at a constant pressure $\left(75 \mathrm{~cm} \mathrm{H}_{2} \mathrm{O}\right)$. The composition of the solution was as follows (in millimoles per liter): $\mathrm{NaCl}$, 


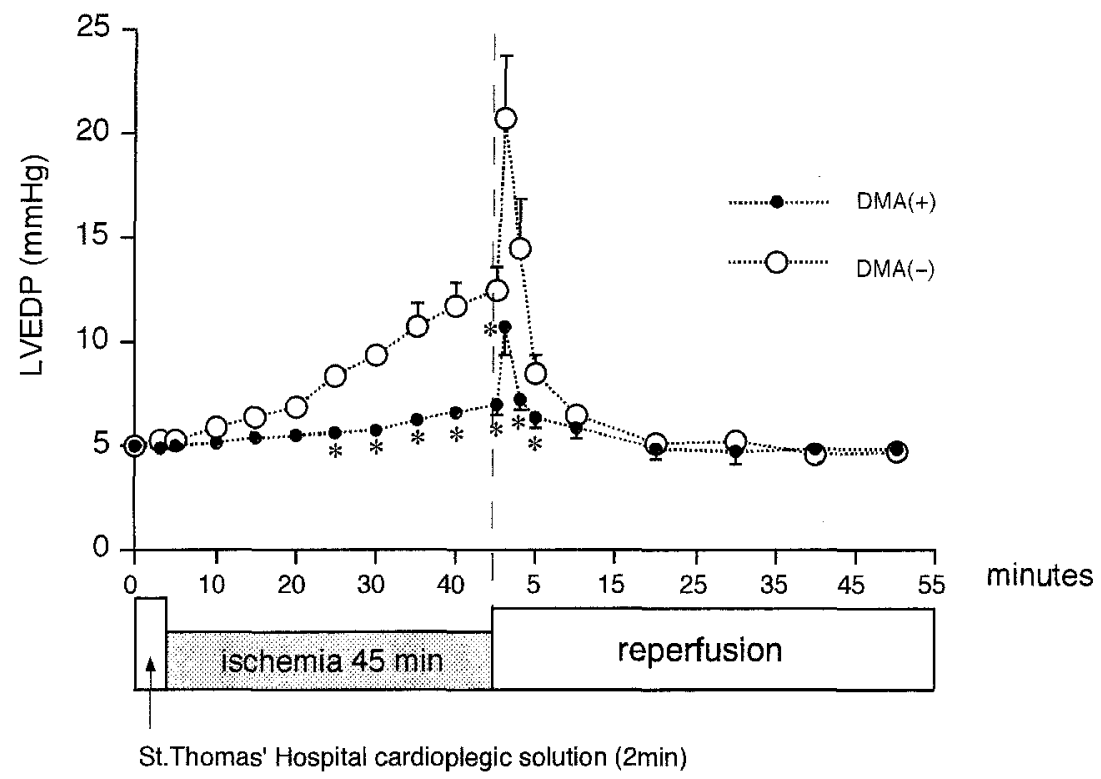

Fig. 2. Changes in the left ventricular end-diastolic pressure (LVEDP) during 45 minutes of ischemia and subsequent 50 minutes of reperfusion. Left ventricular end-diastolic pressure is plotted as a function of time. Zero time is the beginning of cardioplegia and the beginning of reperfusion. Values are presented in means \pm standard error of six untreated hearts (control, open circles) and eight hearts treated with DMA at $10 \mu \mathrm{mol} / \mathrm{L}$ (closed circles). ${ }^{*}$ Significantly different from control at $p<0.05$.

$110 ; \mathrm{KCl}, 16 ; \mathrm{MgCl}_{2}, 16 ; \mathrm{CaCl}_{2}, 1.2$, and $\mathrm{NaHCO}_{3}, 10.0$ (pH 7.8). DMA was added to the St. Thomas' Hospital cardioplegic solution at $10 \mu \mathrm{mol} / \mathrm{L}$. The cardioplegia line was then clamped and global ischemia was produced for 45 minutes at normothermia $\left(37^{\circ} \mathrm{C}\right)$. The hearts were bathed in the cardioplegic solution to avoid oxygen diffusion from the surrounding air. After ischemia, the hearts were reperfused with the control perfusate at $37^{\circ} \mathrm{C}$ for 50 minutes. During the ischemiareperfusion insult, hemodynamic measurements were repeated to document functional deterioration and recovery. The hearts were allowed to beat spontaneously throughout the experiments.

Effects of DMA on hearts subjected to ischemia and reperfusion. Fourteen hearts subjected to normothermic cardioplegic arrest plus ischemia and reperfusion were divided into two groups. In six control hearts, normal St. Thomas' Hospital cardioplegic solution was used for cardioplegia before ischemia. In the remaining eight hearts, DMA was added to the cardioplegic solution in a concentration of $10 \mu \mathrm{mol} / \mathrm{L}$.

Data analysis. All the data were presented as means \pm standard error unless otherwise specified. Hemodynamic data in experiments with nonischemic hearts were expressed as a percentage of pre-drug control values. In ischemia-reperfusion experiments, preischemic function was expressed as an absolute value for each parameter. Postischemic recovery of cardiac function was expressed as an absolute value and as a percentage of its preischemic level. We analyzed NMR data from 15 minutes before ischemia to up to 30 minutes of reperfusion because of a limitation of sam- pling and processing capacity of our computer system, and because hemodynamic recovery of both control and DMA-treated hearts reached almost plateau levels at 30 minutes of reperfusion (Figs. 2 and 3). The unpaired $t$ test was used for comparison of means between the groups. Statistical significance was defined as $p<0.05$.

\section{Results}

Effects of DMA on left ventricular contractility in nonischemic hearts. Treatment of the hearts with DMA at $10 \mu \mathrm{mol} / \mathrm{L}$ resulted in a gradual decrease in heart rate. Heart rate at the end of 45 minutes' exposure to DMA reached $67 \% \pm 10.0 \%$ of the control level $(n=5, p<0.05)$. Average values of left ventricular systolic and developed pressures, $+\mathrm{dp} / \mathrm{dt}$, and $-\mathrm{dp} / \mathrm{dt}$ were virtually unaffected by the DMA treatment. On washing out of DMA for 30 minutes, heart rate recovered to $86 \% \pm$ $6.7 \%$ of control $(p<0.05)$. No appreciable changes in left ventricular end-diastolic pressure occurred throughout the exposure and washing out of DMA.

Hemodynamic function. Averages of heart rate, left ventricular systolic and developed pressures, $+\mathrm{dp} / \mathrm{dt}$, and $-\mathrm{dp} / \mathrm{dt}$ under preischemic condition are summarized in Table I. No significant differences were observed in these baseline parameters between the control and DMA-treated groups. 

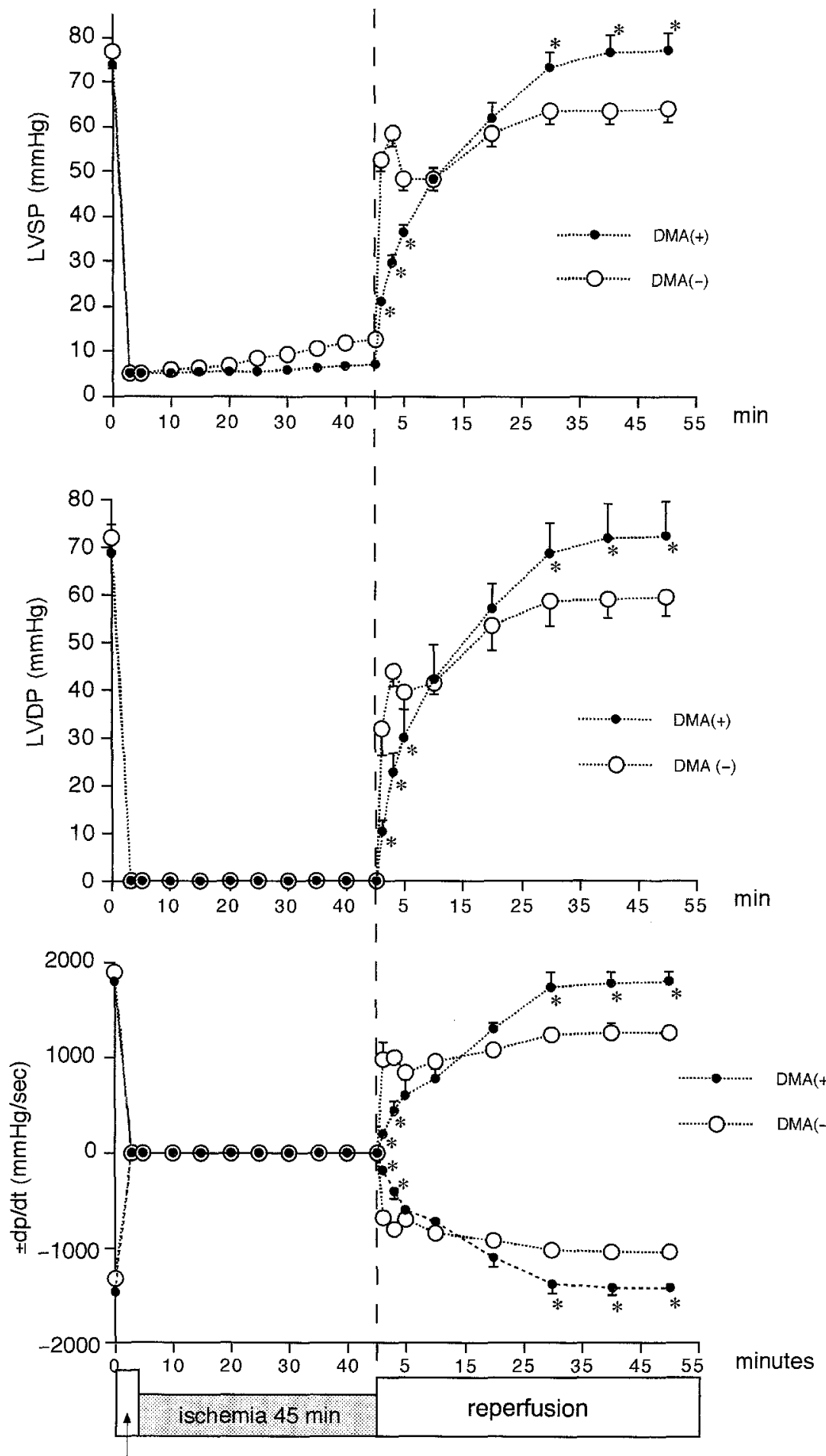

St.Thomas' Hospital cardioplegic solution (2min)

Fig. 3. Changes in the left ventricular systolic pressure ( $L V S P)$, developed pressure ( $L V D P)$, and maximum rate of contraction and relaxation ( $\pm d p / d t)$ during 45 minutes of ischemia and a subsequent 50 minutes of reperfusion. The hemodynamic parameters are plotted as a function of time. Zero time is the beginning of cardioplegia and the beginning of reperfusion. Values are means \pm standard error of six untreated hearts (control, open circles) and of eight hearts treated with DMA at $10 \mu \mathrm{mol} / \mathrm{L}$ (closed circles). * Significantly different from control at $p<0.05$. 
Table I. Baseline hemodynamic parameters during the preischemic condition

\begin{tabular}{lcc}
\hline & $\begin{array}{c}\text { Control group } \\
(n=6)\end{array}$ & $\begin{array}{c}\text { DMA group } \\
(n=8)\end{array}$ \\
\hline HR (beats/min) & $168 \pm 3.3$ & $157 \pm 3.1$ \\
LVDP (mm Hg) & $72 \pm 2.6$ & $68 \pm 6.0$ \\
LVSP (mm Hg) & $77 \pm 2.6$ & $63 \pm 6.0$ \\
+dp/dt (mm Hg/sec) & $1800 \pm 67$ & $1790 \pm 64$ \\
-dp/dt (mm Hg/sec) & $1330 \pm 79$ & $1480 \pm 53$ \\
\hline
\end{tabular}

$H R$, Heart rate; $D M A$, dimethyl amiloride; $L V D P$, left ventricular developed pressure; LVSP, left ventricular systolic pressure. There was no significant difference between the groups. Values are means \pm standard error of the mean.

Sequential changes in left ventricular end-diastolic pressure during and after ischemia are shown in Fig. 2. In the control group $(n=6)$, left ventricular end-diastolic pressure increased progressively during the 45-minute period of ischemia. When the hearts were reperfused, end-diastolic pressure further increased temporarily, giving rise to a peak at 1 minute of reperfusion. Pressure then decayed rather quickly toward the preischemic level within 20 minutes. Left ventricular end-diastolic pressure in the DMA-treated hearts $(n=8)$ also increased during and immediately after ischemia with a similar time course, but the extent of increase was significantly less than control.

Fig. 3 summarizes the changes in left ventricular systolic and developed pressures and $\pm \mathrm{dp} / \mathrm{dt}$ during and after ischemia. In both control and DMAtreated hearts, left ventricular systolic and developed pressures decreased rapidly after initiation of cardioplegia, and the mechanical contraction became undetectable within 1 minute. On reperfusion, left ventricular systolic and developed pressures showed dual phases of recovery; initial rapid recovery within 5 minutes was followed by much slower recovery thereafter. In the control group $(n=6)$, the initial rapid recovery of left ventricular systolic and developed pressures after ischemia peaked at 3 minutes of reperfusion. Then left ventricular systolic and developed pressures decayed a little before the subsequent slower recovery. At 30 minutes of reperfusion, they reached a plateau at $82.4 \% \pm 5.4 \%$ and $75.6 \% \pm 3.2 \%$, respectively. In the DMA-treated group ( $n=8$ ), recovery of left ventricular systolic and developed pressures during reperfusion was slower during the initial 5 minutes, but it was significantly greater during the subsequent period, reaching $99.5 \% \pm 1.7 \%$ and $99.9 \% \pm 1.9 \%$ of their respective preischemic levels at 30 minutes of reper- fusion ( $p<0.05$ vs control). During reperfusion later than 30 minutes, left ventricular systolic and developed pressures further increased, and at 50 minutes they reached $5 \%$ to $11 \%$ above their preischemic levels.

Comparative differences between control and DMA-treated hearts were observed in the recovery of $\pm \mathrm{dp} / \mathrm{dt}$. At 5 minutes of reperfusion, recovery of $+\mathrm{dp} / \mathrm{dt}$ and $-\mathrm{dp} / \mathrm{dt}$ in the DMA-treated group toward the baseline was significantly less than that of the control group. At 30 minutes' reperfusion, however, the recovery of $+\mathrm{dp} / \mathrm{dt}$ and $-\mathrm{dp} / \mathrm{dt}$ in the DMA-treated group was significantly higher than in the control group.

In both the control and DMA-treated hearts, heart rate recovered nearly completely by $10 \mathrm{~min}$ utes of reperfusion, and there was no significant difference between the two groups.

$\mathbf{p H}_{\mathbf{i}}$. Changes in $\mathrm{pH}_{\mathrm{i}}$ during and after ischemia are shown in Fig. 4. The initial (preischemic) level of $\mathrm{pH}_{\mathrm{i}}$ was almost identical in control $(7.25 \pm 0.04, n=$ 6) and DMA-treated hearts $(7.26 \pm 0.05, n=8)$. An infusion of St. Thomas' Hospital solution resulted in a transient increase in $\mathrm{pH}_{\mathrm{i}}$ in both control (up to $7.56 \pm 0.05$ ) and DMA-treated hearts (up to $7.67 \pm$ 0.08 ), probably because of the higher $\mathrm{pH}(7.8)$ of the cardioplegic solution and PCr breakdown (see Discussion).

During the subsequent period of ischemia, $\mathrm{pH}_{\mathrm{i}}$ decreased progressively; its reduction was similar in both groups for 30 minutes of ischemia, but significantly greater in the DMA-treated group than in the control group thereafter. The $\mathrm{pH}_{\mathrm{i}}$ at the end of 45 minutes of ischemia was $6.21 \pm 0.05$ in control hearts and $5.24 \pm 0.17$ in the DMA-treated hearts. During reperfusion, $\mathrm{pH}_{\mathrm{i}}$ in both control and DMAtreated hearts increased rapidly and returned to the preischemic level within 15 minutes. For the first 5 minutes of reperfusion, $\mathrm{pH}_{\mathrm{i}}$ of the DMA-treated hearts was lower than control, but there was no significant difference in the levels during the subsequent period of reperfusion.

High-energy phosphates. Changes in $\mathrm{PCr}, \mathrm{Pi}$, and ATP levels during and after 45 minutes of ischemia are shown in Fig. 5. PCr and ATP values are presented as percentages relative to the preischemic baseline, whereas Pi values are expressed as percentages of the sum of phosphates during the preischemic period. ${ }^{16}$ During ischemia, the rapid degradation of $\mathrm{PCr}$ was balanced by an increase in intracellular Pi. A moderate decrease in ATP was observed as well. 


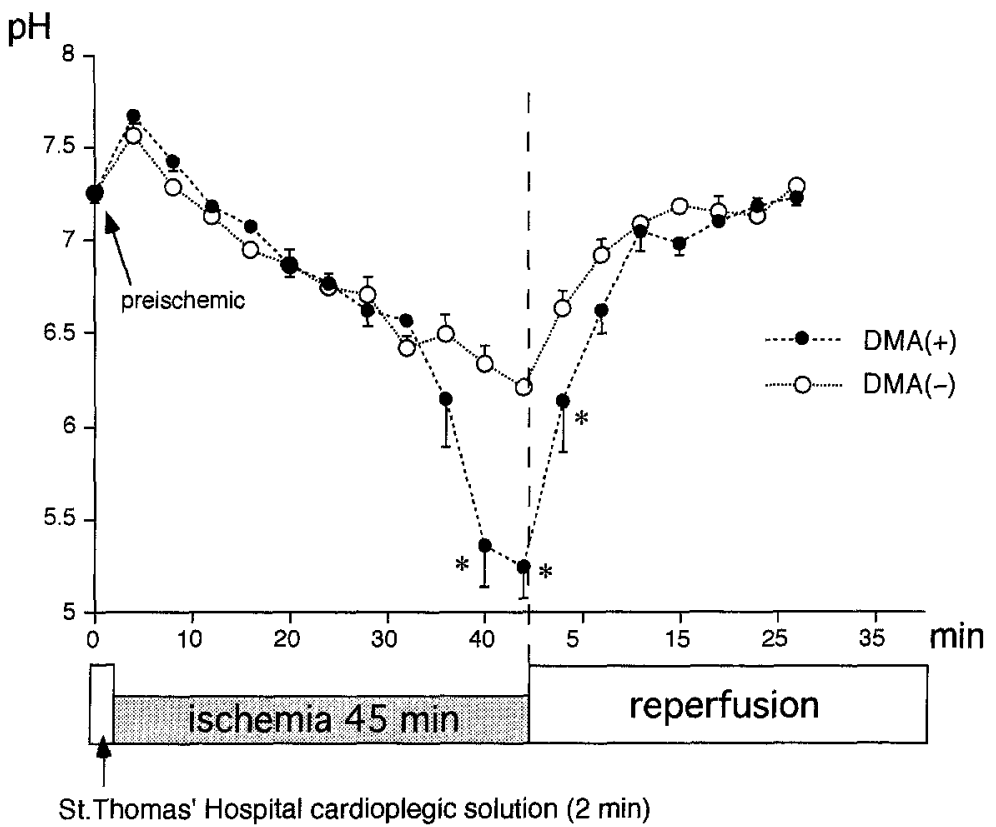

Fig. 4. Changes in $\mathrm{pH}_{\mathrm{i}}$ during 45 minutes of ischemia and a subsequent 30 minutes of reperfusion. Ordinate indicates $\mathrm{pH}_{\mathrm{i}}$ calculated from the chemical shift of Pi peak from $\mathrm{PCr}$ peak in ${ }^{31} \mathrm{P}-\mathrm{NMR}$ spectra. Abscissa is time (in minutes) after the initiation of cardioplegia with St. Thomas' Hospital cardioplegic solution and after the initiation of reperfusion. Values are means \pm standard error of the mean of six untreated hearts (control, open circles) and eight hearts treated with DMA at $10 \mu \mathrm{mol} / \mathrm{L}$ (closed circles). * Significantly different from control at $p<0.05$.

On reperfusion, $\mathrm{PCr}$ was rapidly resynthesized to levels above the preischemic baseline in both control and DMA-treated groups. In association with this change in PCr, Pi decreased rapidly to the preischemic baseline. In contrast, there was no appreciable change in ATP levels during the 30-minute reperfusion period, and there were no significant differences between control and DMA-treated groups in these sequential changes of high-energy phosphates during and after ischemia.

\section{Discussion}

DMA. In the present study we used DMA as a pharmacologic tool to inhibit $\mathrm{Na}^{+}-\mathrm{H}^{+}$exchange in cardiac cell membrane, because of its high potency and high specificity. DMA is 10 to 24 times more potent than amiloride in inhibition of $\mathrm{Na}^{+}-\mathrm{H}^{+}$ exchange, but it is less effective than amiloride in other intrinsic actions unrelated to the antiport. ${ }^{8,14}$ The dose of DMA used in our experiments (10 $\mu \mathrm{mol} / \mathrm{L}$ ) is close to the $50 \%$ inhibitory concentration for DMA to block $\mathrm{Na}^{+}-\mathrm{H}^{+}$exchange in sarcolemmal vesicles, but much less than the $50 \%$ inhibitory concentration to block $\mathrm{Na}^{+}-\mathrm{Ca}^{2+}$ exchange (550 $\mu \mathrm{mol} / \mathrm{L}), \mathrm{Na} / \mathrm{K}$ ATPase $(3000 \mu \mathrm{mol} / \mathrm{L})$, voltagegated $\mathrm{Na}^{+}$channel $(>50 \mu \mathrm{mol} / \mathrm{L})$, and voltagegated $\mathrm{Ca}^{2+}$ channel $(>50 \mu \mathrm{mol} / \mathrm{L}){ }^{8,14}$ DMA also has an advantage over other amiloride analogs in terms of its specificity. ${ }^{15}$

We did not pace the hearts at a constant rate for the sake of simplicity of equipment around the NMR tube. Instead, the hearts were allowed to beat spontaneously throughout each ischemia-reperfusion experiment. This may not invalidate the effects of DMA, because spontaneous beating was terminated by cardioplegia at the onset of ischemia, and there was no significant difference in heart rate between control and DMA-treated groups during the entire period of reperfusion.

The protective actions of DMA against ischemiareperfusion damage to contractility in the present experiments are qualitatively similar to those reported by Meng and associates. ${ }^{6,20,21}$ In experiments using coronary-perfused rat ventricular muscles, they showed that treatment of the preparations with DMA ( 1 to $20 \mu \mathrm{mol} / \mathrm{L}$ ) before 60 minutes of ischemia and at the time of reperfusion reduced the elevation of the resting tension and improved the 


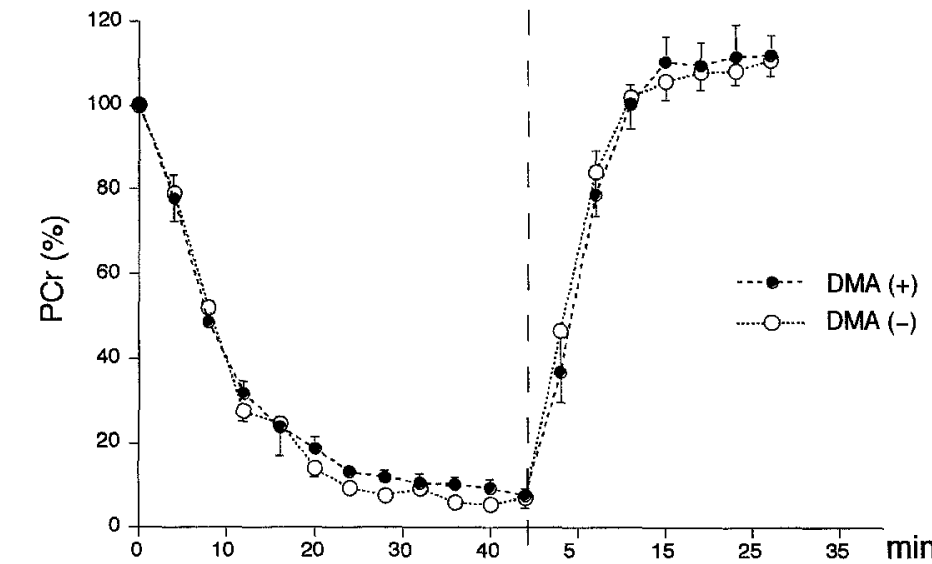

A

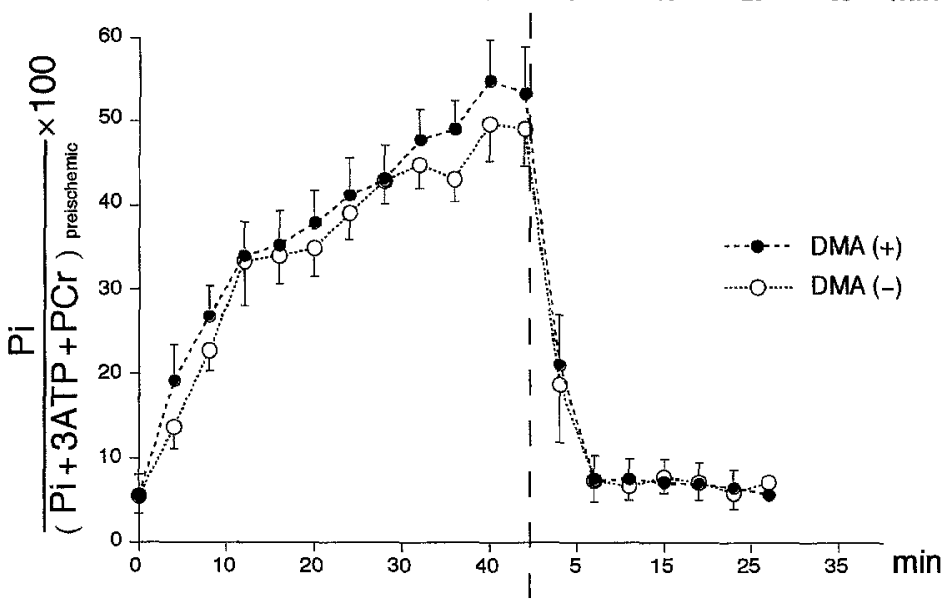

B

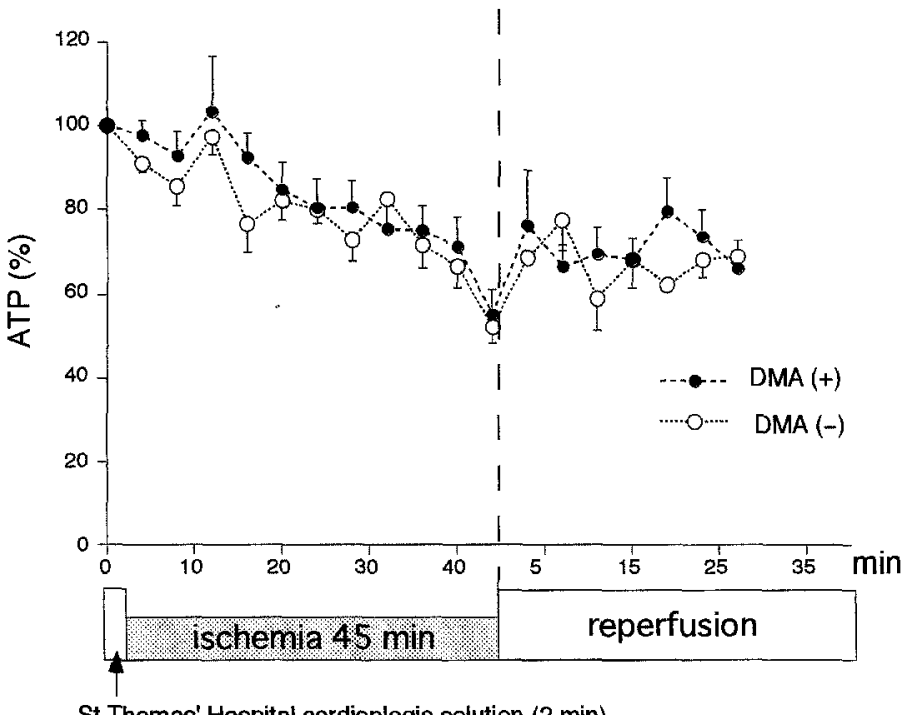

C

Fig. 5. Changes in high-energy phosphates during 45 minutes of ischemia and a subsequent 30 minutes of reperfusion. Ordinates indicate $\mathrm{PCr}$ in $\mathbf{A}, \mathrm{Pi}$ in $\mathbf{B}$, and ATP in C. Abscissas indicate time (in minutes) after the initiation of cardioplegia with St. Thomas' Hospital cardioplegic solution and after the initiation of reperfusion. $\mathrm{PCr}$ and $\mathrm{ATP}$ were expressed as a percentage relative to the preischemic baseline. $\mathrm{Pi}$ was expressed as a percentage of the sum of phosphate from PCr, ATP, and Pi during the preischemic baseline period. Values are means \pm standard error of the mean of six untreated hearts (control, open circles) and eight hearts treated with DMA at $10 \mu \mathrm{mol} / \mathrm{L}$ (closed circles). 
recovery of contractility in a concentration-dependent manner. DMA (10 to $50 \mu \mathrm{mol} / \mathrm{L})$ was also reported to reduce reperfusion arrhythmias ${ }^{8}$ and to reduce the intracellular $\mathrm{Ca}^{2+}$ accumulation during ischemia in rat hearts. ${ }^{10}$ To our knowledge, however, this is the first report to demonstrate that DMA, when added to cardioplegic solution, protects against ischemia-reperfusion injury in mammalian hearts at a concentration with minimal intrinsic actions.

$\mathbf{p H}_{\mathbf{i}}$. The $\mathrm{pH}_{\mathrm{i}}$ at the beginning of ischemia (immediately after infusion of St. Thomas' Hospital cardioplegic solution) increased slightly both in control hearts (from 7.25 to 7.57) and in DMA-treated hearts (from 7.26 to 7.67 ). This transient alkalosis may be attributed in part to the higher $\mathrm{pH}$ level (7.8) of the cardioplegic solution. A rapid breakdown of $\mathrm{PCr}$, which absorbs $\mathrm{H}^{+}$, in the initial period of ischemia (see Fig. 5) may also help to produce this transient alkalosis because it increases intracellular $\mathrm{H}^{+}$buffering capacity. ${ }^{1} \mathrm{pH}_{\mathrm{i}}$ then decreased progressively during the subsequent period of ischemia. DMA treatment did not affect this $\mathrm{pH}_{\mathrm{i}}$ reduction for the initial 30 minutes, but it enhanced the intracellular acidosis during the later period of ischemia. At the end of the 45-minute period of ischemia in the DMA-treated hearts, $\mathrm{pH}_{\mathrm{i}}$ (5.24) was 1.0 unit lower than in control hearts; it recovered rapidly in both control and DMA-treated hearts and returned to the preischemic level by 10 to 15 minutes. In the DMA-treated group during reperfusion, $\mathrm{pH}_{\mathrm{i}}$ was lower than control only at the initial sampling (4 minutes). These findings differ from those of previous reports on the effects of pharmacologic block of $\mathrm{Na}^{+}-\mathrm{H}^{+}$exchange on $\mathrm{pH}_{\mathrm{i}}$ during ischemia-reperfusion injury.

In ${ }^{31} \mathrm{P}-\mathrm{NMR}$ studies using hearts from rats and ferrets, preischemic treatment with amiloride or 5 -( $N$-ethyl- $N$-isopropyl)amiloride (EIPA) was shown to delay $\mathrm{pH}_{\mathrm{i}}$ recovery during early reperfusion without affecting the progressive $\mathrm{pH}_{\mathrm{i}}$ decline during the preceding period of ischemia. ${ }^{5,13}$ Hendrikx and associates ${ }^{9}$ also demonstrated in rabbit hearts that HOE 694 (a new specific $\mathrm{Na}^{+}-\mathrm{H}^{+}$exchange inhibitor) did not affect the $\mathrm{pH}_{\mathrm{i}}$ decline during ischemia, but eliminated the alkaline overshoot at the onset of reperfusion.

The discrepancy between these previous reports and our data may be related to complex regulatory mechanisms of intracellular $\mathrm{H}^{+}$concentration. During ischemia, $\mathrm{H}^{+}$is produced in the cytosol mainly from glycolytic ATP turnover, carbon dioxide retention, and later net ATP degradation. ${ }^{1}$ In the initial period of ischemia, protons are first buffered by intracellular protein histidine residues and by $\mathbf{P i}$, which is a product of $\mathrm{PCr}$ breakdown to help maintain ATP levels. Unbuffered intracellular $\mathrm{H}^{+}$ can leave via sarcolemmal $\mathrm{H}^{+}$-lactate cotransporter, $\mathrm{Na}^{+}-\mathrm{H}^{+}$exchange, and $\mathrm{Na}^{+}-\mathrm{HCO}_{3}-$ coinflux. ${ }^{1,22} \mathrm{As}$ ischemia progresses, however, further $\mathrm{H}^{+}$efflux is likely to be opposed by interstitial $\mathrm{H}^{+}$accumulation, leading to a decrease of transsarcolemmal $\mathrm{H}^{+}$gradient, and by intracellular $\mathrm{Na}^{+}$accumulation, caused by an inhibition of sarcolemmal $\mathrm{Na} / \mathrm{K}$ ATPase. ${ }^{3}$ Competition of $\mathrm{H}^{+}$and $\mathrm{Ca}^{2+}$ in the intracellular binding sites ${ }^{23}$ also affects the free $\mathrm{H}^{+}$ concentration in the cytosol. Accumulation of intracellular $\mathrm{Ca}^{2+}$ during ischemia thus favors a further decrease in $\mathrm{pH}_{\mathrm{i}}$ through displacement of $\mathrm{H}^{+}$from intracellular buffering sites by $\mathrm{Ca}^{2+}$. An active $\mathrm{Na}^{+}-\mathrm{H}^{+}$exchange process is not necessarily related to $\mathrm{pH}$ regulation, because coupling of this process with $\mathrm{Cl}^{-}-\mathrm{HCO}_{3}$ - exchange $\left(\mathrm{Cl}^{-}\right.$influx) results in zero acid extrusion, and net $\mathrm{NaCl}$ influx, reported to be a mechanism for volume regulation. ${ }^{24,25} \mathrm{~A}$ decrease of $\mathrm{H}^{+}$influx via $\mathrm{Na}^{+}-\mathrm{H}^{+}$exchange was reported to reduce the $\mathrm{H}^{+}$production by anaerobic glycolysis. ${ }^{11,26}$ The ultimate effect of pharmacologic inhibition of $\mathrm{Na}^{+}-\mathrm{H}^{+}$exchange on $\mathrm{pH}_{\mathrm{i}}$, therefore, depends on the relative importance of this antiport in the total capacity of $\mathrm{H}^{+}$buffering and extrusion and on the secondary modulation of intracellular $\mathrm{H}^{+}$generation.

The activity of $\mathrm{Na}^{+}-\mathrm{H}^{+}$exchange is known to be inhibited by lowering the extracellular $\mathrm{pH}^{27,28}$ The $\mathrm{pH}$ of the cardioplegic solution used in the present study (7.8) is higher than that of ordinary buffer perfusates (7.4) used by other investigators. This might have helped to maintain greater $\mathrm{Na}^{+}-\mathrm{H}^{+}$ exchange activity during ischemia in our experiments. Other conditions that increase the $\mathrm{Na}^{+}-\mathrm{H}^{+}$ exchange activity, such as sufficient transsarcolemmal $\mathrm{Na}^{+}$gradient or phosphorylation of the exchanger via protein kinase $C$, might have been different between the present experiments and the previous studies. ${ }^{2}$ If the relative contribution of $\mathrm{Na}^{+}-\mathrm{H}^{+}$exchange to the net $\mathrm{H}^{+}$buffering and extrusion capacity of cardiac muscle is small, an inhibition of the antiport will be easily masked by other multiple regulatory mechanism as described earlier and will result in no observable change in $\mathrm{pH}_{\mathrm{i}}$.

On reperfusion, a prompt washout of extracellular $\mathrm{H}^{+}$and metabolites is thought to lead to a rapid efflux of accumulated intracellular $\mathrm{H}^{+}$through a passive efflux of lactate and carbon dioxide, as well 
as an active $\mathrm{H}^{+}$extrusion mechanism $\left(\mathrm{Na}^{+}-\mathrm{H}^{+}\right.$ exchange and $\mathrm{Na}^{+}-\mathrm{HCO}_{3^{-}}$coinflux)., ${ }^{3,22}$ In the present experiments, treatment with DMA caused only a slight delay in $\mathrm{pH}_{\mathrm{i}}$ recovery during reperfusion, suggesting a relatively small contribution of $\mathrm{Na}^{+}-\mathrm{H}^{+}$exchange to the $\mathrm{pH}_{\mathrm{i}}$ recovery during reperfusion. In a recent extensive study using ferret hearts, Vandenberg, Metcalfe, and Grace ${ }^{22}$ have concluded that the $\mathrm{pH}_{\mathrm{i}}$ recovery during reperfusion is principally mediated by metabolite washout, that is, lactate and carbon dioxide extrusion, and that $\mathrm{Na}^{+}-\mathrm{H}^{+}$exchange and $\mathrm{HCO}_{3}$ - influx may contribute as much as $20 \%$ to $35 \%$ of net $\mathrm{H}^{+}$efflux.

During ischemia, the exchanger is partially inhibited by low extracellular $\mathrm{pH},{ }^{27,28}$ but this inhibition can be overdriven by intracellular acidosis. ${ }^{28} \mathrm{~A}$ rise in intracellular $\mathrm{Na}^{+}$during ischemia and its suppression by amiloride or EIPA have been documented by ${ }^{23} \mathrm{Na}-\mathrm{NMR}{ }^{10,13} \mathrm{~A}$ rise in cytosolic $\mathrm{Ca}^{2+}$ during ischemia and its suppression by amiloride were also demonstrated in ${ }^{19} \mathrm{~F}$-NMR. ${ }^{10}$ The present data indicating an enhancement of $\mathrm{pH}_{\mathrm{i}}$ reduction and an attenuation of left ventricular end-diastolic pressure elevation in DMA-treated hearts from the later period of ischemia to early reperfusion are in agreement with those of previous reports suggesting an important role of $\mathrm{Na}^{+}-\mathrm{H}^{+}$exchange during ischemia. $\mathrm{Na}^{+}-\mathrm{H}^{+}$exchange blockers may improve the functional recovery of cardiac muscle by limiting the $\mathrm{Na}^{+}$gain during ischemia and by inhibiting the additional rise of $\mathrm{Na}^{+} \mathrm{i}$ on reperfusion when the partial block of external acidification on $\mathrm{Na}^{+}-\mathrm{H}^{+}$ exchange is suddenly relieved. Intracellular acidification during the early period of reperfusion would also favor the cardiac muscle by inhibition of $\mathrm{Ca}^{2+}$ entry via $\mathrm{Na}^{+}-\mathrm{Ca}^{2+}$ exchange, coupling of $\mathrm{Ca}^{2+}$ to contractile elements, and other $\mathrm{Ca}^{2+}$-induced reactions. $^{3}$

High-energy phosphates. There is considerable controversy among previous reports whether the protective effects of $\mathrm{Na}^{+}-\mathrm{H}^{+}$exchange blockers are associated with an improvement of energy metabolism. In experiments using rat hearts, some investigators showed that amiloride had no significant effects on the reduction of ATP and PCr during ischemia and reperfusion. ${ }^{4,10}$ In experiments by other investigators using rat or rabbit hearts, ${ }^{9,13}$ however, EIPA or HOE 694 was shown to reduce ATP depletion during ischemia and to improve recovery of $\mathrm{PCr}$ and ATP during reperfusion. In the present experiments, preischemic treatment with DMA did not affect PCr breakdown, $\mathrm{Pi}$ accumula- tion, or ATP depletion during 45 minutes of ischemia. The PCr resynthesis and $\mathrm{Pi}$ reduction during reperfusion were unaffected as well.

The reason for the different observations is unclear. Depletion of high-energy phosphates during ischemia and reperfusion could be ameliorated by an inhibition of $\mathrm{Na}^{+}-\mathrm{H}^{+}$exchange via a reduction of intracellular $\mathrm{Na}^{+}$and $\mathrm{Ca}^{2+}$ overload, ${ }^{2,3}$ because a great deal of ATP is used for extrusion of $\mathrm{Na}^{+}$and for storage of $\mathrm{Ca}^{2+}$ in the sarcoplasmic reticulum. $\mathrm{Ca}^{2+}$ overload also activates ATP use by many ATPases and inhibits mitochondrial oxidative phosphorylation to produce ATP. ${ }^{29,30}$ The increase of left ventricular end-diastolic pressure, which reflects $\mathrm{Ca}^{2+}$ overload, and the decrease in ATP observed in our control experiments of ischemia and reperfusion are appreciably less than those reported by Hendrikx, ${ }^{9}$ Pike, ${ }^{13}$ and their associates. This is probably due to the cardioprotective action of St. Thomas' Hospital cardioplegic solution in our experiments. Beneficial effects of $\mathrm{Na}^{+}-\mathrm{H}^{+}$inhibition on the energy metabolism might be detected only when the $\mathrm{Na}^{+}$and $\mathrm{Ca}^{2+}$ overload is above a certain critical level. This issue remains to be tested.

\section{Conclusion}

The present study has revealed that an application of DMA at an appropriate concentration to cardioplegic solution at the onset of ischemia causes a good improvement of ventricular function during the subsequent period of reperfusion. This beneficial effect is associated with an enhancement of $\mathrm{pH}_{\mathrm{i}}$ reduction during late ischemia and early reperfusion but no appreciable modification of energy metabolism. It is suggested that $\mathrm{Na}^{+}-\mathrm{H}^{+}$exchange plays an important role not only during reperfusion but also during ischemia for the development of postischemic cardiac dysfunction, most likely by inducing intracellular $\mathrm{Na}^{+}$and $\mathrm{Ca}^{2+}$ overload.

DMA seems to have an interesting therapeutic potential in cardiac surgery to ameliorate postarrest cardiac dysfunction or postischemic myocardial stunning. More extensive experimental studies, however, will have to be carried out before the exact clinical usefulness of this compound can be discussed. For instance, in cardiac operations in human beings, unlike the present in vitro experiments, the hearts are reperfused with blood. Many experimental and clinical studies have shown that $\mathrm{Na}^{+}-\mathrm{H}^{+}$ exchange plays important roles in activation of platelets and neutrophils, which are known to release various cardiotoxic factors on reperfusion such 
as arachidonic acid, thromboxane $\mathrm{A}_{2}$, and leukotriene $\mathrm{B}_{4}{ }^{2}$ If these processes are inhibited by DMA, its beneficial effects against ischemia-reperfusion injury would be amplified. DMA might also modulate the volume regulation process ${ }^{24,25}$ of blood cells and cardiac cells by inhibiting $\mathrm{Na}^{+}-\mathrm{H}^{+}$exchange. These aspects of the drug action remain to be elucidated.

We thank Makoto Naruse (Aichi Medical University) for his technical assistance in the conduct of these experiments.

\section{REFERENCES}

1. Dennis SC, Gevers W, Opie LH. Protons in ischemia: Where do they come from; Where do they go to? J Mol Cell Cardiol 1991;23:1077-86.

2. Karmazyn M, Moffat MP. Role of $\mathrm{Na}^{+} / \mathrm{H}^{+}$exchange in cardiac physiology and pathophysiology: mediation of myocardial reperfusion injury by the $\mathrm{pH}$ paradox. Cardiovasc Res 1993;27:915-24.

3. Scholz W, Albus U. Potential of selective sodium-hydrogen exchange inhibitors in cardiovascular therapy. Cardiovasc Res 1995;29:184-8.

4. Tani M, Neely JR. Role of intracellular $\mathrm{Na}^{+}$in $\mathrm{Ca}^{2+}$ overload and depressed recovery of ventricular function of reperfused ischemic rat hearts: possible involvement of $\mathrm{H}^{+}$. $\mathrm{Na}^{+}$and $\mathrm{Na}^{+}-\mathrm{Ca}^{2+}$ exchange. Circ Res 1989;65:1045-56.

5. Khandoudi N, Bernard M, Cozzone P, Feuvray D. Intracellular $\mathrm{pH}$ and role of $\mathrm{Na}^{+} / \mathrm{H}^{+}$exchange during ischemia and reperfusion of normal and diabetic rat hearts. Cardiovasc Res 1990;24:873-8.

6. Meng H, Pierce GN. Protective effects of 5-(N,N-dimethyl)amiloride on ischemia-reperfusion injury in hearts. Am $\mathrm{J}$ Physiol 1990;258:H1615-9.

7. Moffat MP, Karmazyn M. Protective effects of the potent $\mathrm{Na} / \mathrm{H}$ exchange inhibitor methylisobutyl amiloride against post-ischemic contractile dysfunction in rat and guinea-pig hearts. J Mol Cell Cardiol 1993;25:959-71.

8. Dennis SC, Coetzee WA, Cragoe EJ Jr, Opie LH. Effects of proton buffering and of amiloride derivatives on reperfusion arrhythmias in isolated rat hearts: possible evidence for an arrhythmogenic role of $\mathrm{Na}^{+}{ }_{-} \mathrm{H}^{+}$exchange. Circ Res 1990;66: $1156-9$.

9. Hendrikx M, Mubagwa $K$, Verdonck F, Overloop K, Van Hecke $\mathrm{P}$, Vanstapel $\mathrm{F}$, et al. New $\mathrm{Na}^{+}-\mathrm{H}^{+}$exchange inhibitor HOE 694 improves postischemic function and high-energy phosphate resynthesis and reduces $\mathrm{Ca}^{2+}$ overload in isolated perfused rabbit heart. Circulation 1994;89:2787-98.

10. Murphy E, Perlman M, London RE, Steenbergen C. Amiloride delays the ischemia-induced rise in cytosolic free calcium. Circ Res 1991;68:1250-8.

11. Scholz W, Albus U, Lang HJ, Linz W, Martorana PA, Englert $\mathrm{HC}$, et al. HOE694, a new $\mathrm{Na}^{+} / \mathrm{H}^{+}$exchange inhibitor and its effects in cardiac ischaemia. Br J Pharmacol 1993;109:562-8.

12. Scholz W, Albus U, Linz W, Martorana P, Lang HJ, Scholkens BA. Effects of $\mathrm{Na}^{+} / \mathrm{H}^{+}$exchange inhibitors in cardiac ischemia. J Mol Cell Cardiol 1992,24:731-40.
13. Pike MM, Luo CS, Clark MD, Kirk KA, Kitakaze, M, Madden MC, et al. NMR measurements of $\mathrm{Na}^{+}$and cellular energy in ischemic rat heart: role of $\mathrm{Na}^{+}-\mathrm{H}^{+}$exchange. Am J Physiol 1993;265:H2017-26.

14. Kleyman TR, Cragoe EJ Jr. Amiloride and its analogs as tools in the study of ion transport. J Membrane Biol 1988; 105:1-21.

15. Hotta Y, Ando H, Takeya K, Sakakibara J. Direct measurement of increased myocardial cellular ${ }^{23} \mathrm{Na}$ NMR signals in perfused guinea-pig heart induced by dihydroouabain and grayanotoxin-I. Mol Cell Biochem 1994;139: 59-70.

16. Kirkles JH, Ruigrok TJC, Van Echteld CJA, Meijler FL. Low $\mathrm{Ca}^{2+}$ reperfusion and enhanced susceptibility of the postischemic heart to the calcium paradox. Circ Res 1989;64:1158-64.

17. Flaherty JT, Weisfeldt ML, Bulkley BH, Gardner TJ, Gott VL, Jacobus WE. Mechanisms of ischemic myocardial cell damage assessed by phosphorus-31 nuclear magnetic resonance. Circulation 1982;65:561-71.

18. Moon RB, Richards JH. Determination of intracellular $\mathrm{pH}$ by ${ }^{31} \mathrm{P}$ magnetic resonance. J Biol Chem 1973;248:7276-8.

19. Pierce GN, Cole WC, Liu K, Massaeli H, Maddaford TG, Chen YJ, et al. Modulation of cardiac performance by amiloride and several selected derivatives of amiloride. J Pharmacol Exp Ther 1993;265:1280-91.

20. Meng H, Pierce GN. Involvement of sodium in the protective effect of 5 -(N,N-dimethyl)-amiloride on ischemia-reperfusion injury in isolated rat ventricular wall. J Pharmacol Exp Ther 1991;256:1094-100.

21. Meng H, Lonsberry BB, Pierce GN. Influence of perfusate $\mathrm{pH}$ on the postischemic recovery of cardiac contractile function: involvement of sodium-hydrogen exchange. J Pharmacol Exp Ther 1991;258:772-7.

22. Vandenberg JI, Metcalfe JC, Grace AA. Mechanisms of pHi recovery after global ischemia in the perfused heart. Circ Res 1993;72:993-1003.

23. Orchard $\mathrm{CH}$, Kentish JC. Effects of changes of $\mathrm{pH}$ on the contractile function of cardiac muscle. Am J Physiol 1990; 258:C967-81.

24. Cala PM, Anderson SE, Cragoe EJ. $\mathrm{Na} / \mathrm{H}$ exchange-dependent cell volume and $\mathrm{pH}$ regulation and disturbances. Comp Biochem Physiol 1988;90a:551-5.

25. Rothstein $\mathrm{A}$. The $\mathrm{Na}^{+} / \mathrm{H}^{+}$exchange system in cell $\mathrm{pH}$ and volume control. Rev Physiol Biochem Pharmacol 1989;112: 235-57.

26. Rouslin W. Protonic inhibition of the mitochondrial oligomycin-sensitive adenosine $5^{\prime}$-triphosphatase in ischemic and autolyzing cardiac muscle. J Biol Chem 1983;258:9657-61.

27. Lazdunski $\mathbf{M}$, Frelin $C$, Vigne $P$. The sodium/hydrogen exchange system in cardiac cells: its biochemical and pharmacological properties and its role in regulating internal concentrations of sodium and internal $\mathrm{pH}$. J Mol Cell Cardiol $1985 ; 17: 1029-42$

28. Vaughan-Jones $\mathrm{RD}, \mathrm{Wu} \mathrm{M}-\mathrm{L}$. Extracellular $\mathrm{H}^{+}$inactivation of $\mathrm{Na}^{+}-\mathrm{H}^{+}$exchange in the sheep cardiac Purkinje fibre. J Physiol 1990;428:441-66.

29. Katz AM, Reuter H. Cellular calcium and cardiac cell death. Am J Cardiol 1979;44:188-90.

30. Nayler WG. The role of calcium in the ischemic myocardium. Am J Pathol 1981;102:262-70. 